\title{
Earthquake Early Warning ShakeAlert System: West Coast Wide Production Prototype
}

\section{by Monica D. Kohler, Elizabeth S. Cochran, Doug Given, Steve Guiwits, Doug Neuhauser, Ivan Henson, Renate Hartog, Paul Bodin, Victor Kress, Stephen Thompson, Claude Felizardo, Jeff Brody, Rayo Bhadha, and Stan Schwarz}

\begin{abstract}
Earthquake early warning (EEW) is an application of seismological science that can give people, as well as mechanical and electrical systems, up to tens of seconds to take protective actions before peak earthquake shaking arrives at a location. Since 2006, the U.S. Geological Survey has been working in collaboration with several partners to develop EEW for the United States. The goal is to create and operate an EEW system, called ShakeAlert, for the highest risk areas of the United States, starting with the West Coast states of California, Oregon, and Washington. In early 2016, the Production Prototype v.1.0 was established for California; then, in early 2017, v.1.2 was established for the West Coast, with earthquake notifications being distributed to a group of beta users in California, Oregon, and Washington. The new ShakeAlert Production Prototype was an outgrowth from an earlier demonstration EEW system that began sending test notifications to selected users in California in January 2012. ShakeAlert leverages the considerable physical, technical, and organizational earthquake monitoring infrastructure of the Advanced National Seismic System, a nationwide federation of cooperating seismic networks. When fully implemented, the ShakeAlert system may reduce damage and injury caused by large earthquakes, improve the nation's resilience, and speed recovery.
\end{abstract}

\section{INTRODUCTION}

Earthquake early warning (EEW) is the capability to automatically identify and characterize an earthquake quickly as it is beginning, estimate the likely intensity of ground shaking that will result, and deliver warnings to people and systems that may experience shaking before said shaking arrives at their location (Nakamura, 1988; Wu et al., 1998; Hoshiba et al., 2008). Earthquakes pose a national challenge because more than 143 million Americans live in areas of significant seismic risk that are located across 39 states (Jaiswal et al., 2015). To reduce the impact of earthquakes in the United States, an EEW system, known as ShakeAlert, is being developed. The U.S. Geological Survey (USGS), along with partner organizations, is developing and operating ShakeAlert for the highest-risk areas of the United States by leveraging the current earthquake monitoring capabilities of the Advanced National Seismic System (ANSS). The ANSS is a federation of USGS-supported seismic networks that delivers real-time earthquake information for the nation (USGS, 1999). EEWs have the potential to give people and systems the necessary time to conduct preemptive protective actions such as automatically slowing trains, opening fire station doors, and sending elevators to the nearest floor, in preparation for impending ground shaking (Strauss and Allen, 2016). Alerts associated with aftershocks after a large earthquake may also provide useful decision-making information about whether or not to temporarily suspend rescue and repair operations (Bakun et al., 1994).

In February 2016, the official ShakeAlert production version (Production Prototype 1.0) went live in California and began providing notifications to a small group of community participants. In April 2017, Production Prototype 1.2 went live to the entire West Coast (California, Oregon, and Washington). The ShakeAlert system will initially provide alerts for the western United States, as most of the nation's earthquake risk is concentrated on the West Coast of the United States (Federal Emergency Management Agency [FEMA], 2008). The Production Prototype is a preoperational version of ShakeAlert that continues to test and improve rapid earthquake alerting methodologies. This next-generation system is not yet distributing warnings to the general public, but it does allow selected early adopters to develop and deploy pilot implementations that initiate protective actions based on ShakeAlert earthquake warnings.

Since 2006, the USGS has supported development of an EEW system for the United States in collaboration with partners including Caltech, University of California at Berkeley, the University of Washington, the California Office of Emergency Services, and the California Geological Survey. More recently, the University of Oregon, the University of Nevada in Reno, Central Washington University, and UNAVCO have joined the collaboration. Those efforts resulted in a demonstration system called ShakeAlert that was sending test notifications to a small number of users; these users included emergency response organ- 
izations, utilities, rail operators, and private companies. This system sent notifications starting in January 2012 and continued to do so until the production system for California came online in 2016 (Given et al., 2014). ShakeAlert has detected hundreds of earthquakes of $\mathbf{M} 2.5$ and larger in California, including the 29 March 2014 M 5.1 La Habra mainshock that was detected $4.2 \mathrm{~s}$ after the origin time and the 24 August 2014 M 6.0 South Napa earthquake that provided 5-8 s of warning to beta users in the San Francisco Bay area.

The ShakeAlert architecture contains multiple components, including data sources, waveform processors, event originators and associators, and an alert generator. Data sources comprise continuous waveforms and derived EEW parameters from regional seismic networks; however, future developments may include Global Navigation Satellite System (GNSS) data and additional data streams. The waveform processors analyze high-sample-rate time-series data to generate picks of phase arrivals and calculate relevant early warning parameters. Event originators associate triggers and/or phase picks and their derived parameters to declare an event and characterize its origin time, location, and evolving magnitude within seconds of initiation.

The system will provide a variety of data products. Public alerts will be issued for moderate to large earthquakes, and a more information-rich data stream that includes the shaking intensity and time until shaking occurs at a user's location will be provided to institutional users, both public and private. Public alerts will not be distributed until the ShakeAlert system products meet minimum quality and reliability standards; these standards are currently being developed on a region-by-region basis. The initial goal has been to build ShakeAlert for the three states where the earthquake risk is highest (California, Oregon and Washington); however, feasibility studies of expanding ShakeAlert to other states have been conducted (Thelen et al., 2016).

During an earthquake, $P$ waves radiate first from a rupturing fault, traveling at more than $6 \mathrm{~km} / \mathrm{s}$ from the earthquake source. These rarely cause damage because of their relatively small amplitudes and vertical polarizations; however, it is important to note that damage from vertical ground motion, particularly in the near field of large earthquakes, has been documented (Papazoglou and Elnashaj, 1996). $S$ waves travel at about $3.5 \mathrm{~km} / \mathrm{s}$, or about $60 \%$ the speed of the $P$ waves. Their typically larger amplitudes and predominantly horizontal polarizations cause relatively intense ground shaking and are more likely to cause damage to buildings and other civil structures (Bozorgnia and Bertero, 2004). Other potentially more damaging surface waves arrive after the $S$ wave (Graves et al., 1998). As the waves radiate outward, the interval between the $P$ and $S$ waves grows. This $S-P$ time is about $1 \mathrm{~s}$ for every $8 \mathrm{~km}$ of separation between any specific location and the earthquake hypocenter. A networkbased system, such as the ShakeAlert system, uses regional arrays of seismometers to ensure that sensors are located close to potential earthquake sources in the region. Individual sensors send continuous waveform data to a central processing hub that detects statistically significant new ground motions, aggregates detections from the network (or multiple networks), makes automated computational decisions, and sends region-wide alerts.
Fast, scientifically sophisticated algorithms analyze the ground motions recorded by the sensors to distinguish among noise (e.g., thunder, traffic, and explosions), small earthquakes, and potentially damaging earthquakes. It has been demonstrated empirically that by examining the characteristics (e.g., peak displacement and predominant period) of the first few seconds of the $P$ wave, the size of an earthquake can be inferred (Nakamura, 1988; Kanamori, 2005; Olson and Allen, 2005; Wu et al., 2007), at least up to $\mathbf{M} 6.5$ or 7.0; at this point, source durations are less than the time window used to infer the magnitude, and ground motions may begin to saturate (Lancieri and Zollo, 2008; Murphy and Nielson, 2009; Satriano et al., 2011). Once the location and a preliminary magnitude are known, the initial ground-shaking levels can be estimated for the affected region using groundmotion prediction equations, and alerts can be sent to users. As the earthquake evolves, the magnitude of the event is updated, and the region is also expected to exceed the ground-motion threshold used for alerting. The area closest to the epicenter may receive little or no warning. The size of this zone depends on multiple factors, such as: how close seismic sensors are to the epicenter, the depth of the earthquake, the alert speed of the EEW system, and the threshold of shaking used to issue an alert. The speed of the system is affected by factors such as: delays in data transmission and processing, how much of the $P$ wave must be examined to determine magnitude, and how many station reports are needed to declare an alert. There is always a tradeoff between speed and accuracy; greater speed means a greater chance of false alarms and less accurately estimated source parameters. Technically sophisticated end users will likely choose their optimal alert threshold by taking into account their tolerance for false alerts. For example, users may decide to initiate action when an alert has larger uncertainty and/or at a lower alert threshold to ensure they receive a timely alert and have enough time to initiate an action before peak shaking arrives. In general, users who choose a lower alert threshold will receive longer warning times (Meier, 2017; Minson et al., 2017).

A testing and certification platform for application to the foundational EEW algorithms is an important component of the system and is addressed in a companion paper submitted to this same volume (Cochran et al., 2017). Developing the current West Coast ANSS networks to the level needed for robust EEW requires more stations, improved data telemetry, additional testing and certification of software algorithms, development of mass alert mechanisms, and education of both the public and institutional users. One strategy for expanding the seismic network coverage through larger numbers of compact sensors would be to pursue the integration of data from inexpensive microelectromechanical systems sensors that are hosted by volunteers (Cochran et al., 2009; Clayton et al., 2011, 2015; Given et al., 2014; Lawrence et al., 2014).

\section{SHAKEALERT SYSTEM COMPONENTS}

A large-scale network-based EEW system, such as ShakeAlert, has five major components: a dense sensor network to record ground motion, data telemetry to carry field data to the central 
processing centers, data processing and alert centers, paths for distributing alert information to users, and end-user applications together with education and training. These are also the same elements needed for routine earthquake monitoring, and they already exist in the ANSS West Coast networks: the California Integrated Seismic Network (CISN) and the Pacific Northwest Seismic Network (PNSN) that covers Washington and Oregon. ShakeAlert leverages the extensive investment in infrastructure and software residing in these networks, as well as their significant human expertise in seismology, geodesy, telecommunications, seismic network operations, software development, and public outreach.

\section{Sensor Networks}

The ANSS networks currently operate seismic (Fig. 1) and GNSS sensors in California and the Pacific Northwest, and they import data streams from cooperating networks. The sensors deliver real-time data to three regional ANSS Tier 1 centers; a Tier 1 center consists of a regional seismic network covering a broad area and an established data processing center (USGS, 2014). These centers, located in Seattle, northern California, and southern California, also receive real-time data feeds from other ANSS contributors. These contributors are both public and private, though not all of these sensors are suitable for EEW. EEW seismometer sensor types include broadband, short period and strong motion. Broadband sensors typically record velocity time series and are the most sensitive to low-amplitude motions (i.e., producing high signal-to-noise time series) for the widest range of seismic frequencies, but they can clip for large amplitudes. Short-period sensors also typically record velocity time series and are sensitive to low-amplitude ground motions for a more limited range of frequencies that depends on the sensor, but they can clip for large amplitudes. Strongmotion sensors are not as sensitive to low-amplitude motions (i.e., lower signal-to-noise time series), but they are least likely to clip for large amplitude accelerations. EEW algorithms use channels with sample rates of $80-100$ samples/s if these data are available and 40-50 samples/s channels if higher samplerate data are not available. There are currently about 760 stations that contribute data to the ShakeAlert system (Fig. 1). The USGS ShakeAlert implementation plan calls for seismic network station spacing of $20 \mathrm{~km}$ or less for EEW; $10 \mathrm{~km}$ station spacing would maximize the warning time in densely populated areas and provide ground-motion data for ShakeMaps, and stations should be placed within $5 \mathrm{~km}$ of mapped fault traces (Given et al., 2014). However, at the current time, many ANSS stations are short-period sensors that clip during

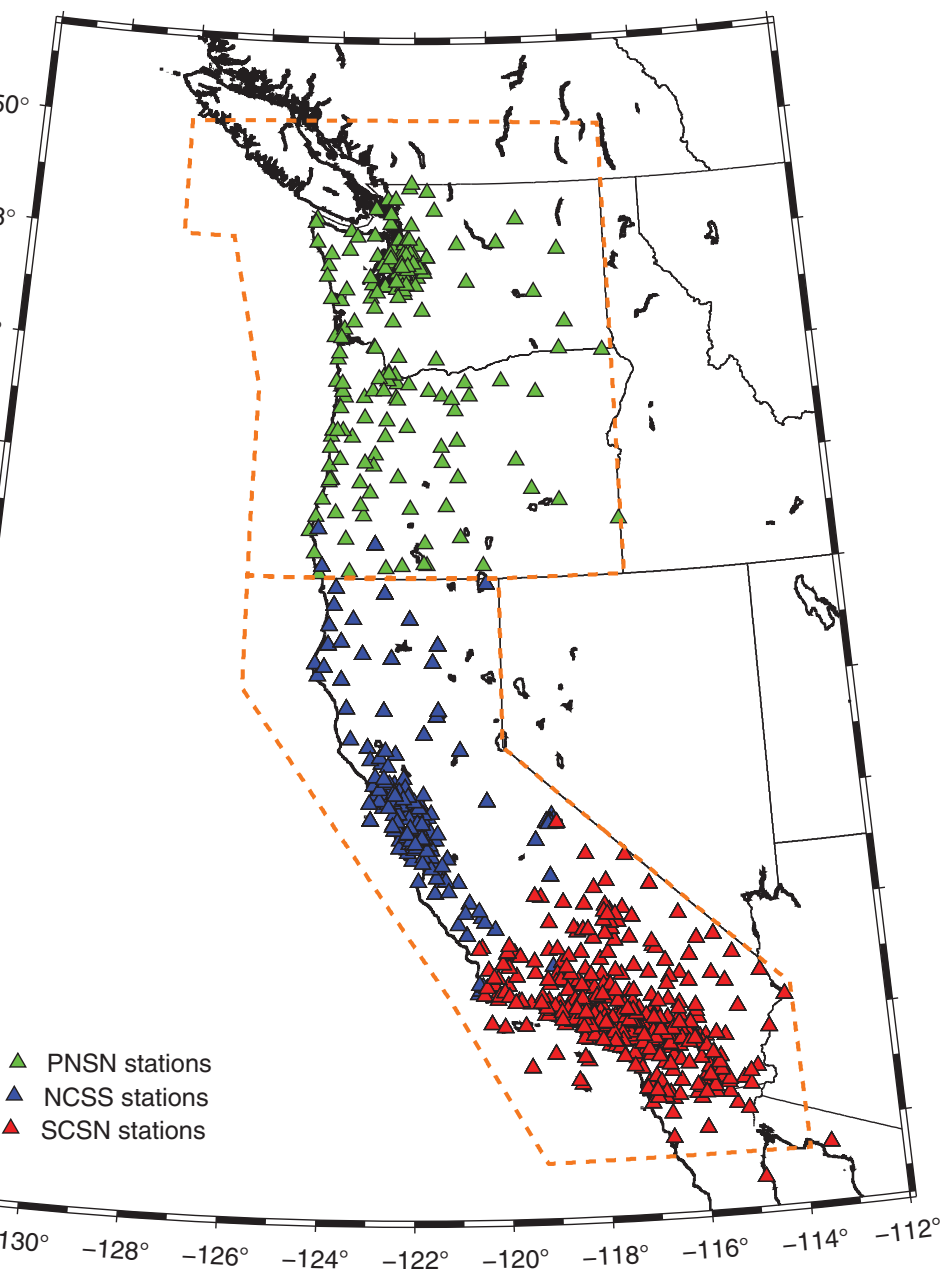

- Figure 1. Advanced National Seismic System (ANSS) seismic network stations in the western United States, making up the three Tier 1 regional seismic network ters in California and Washington that operate ShakeAlert and send alerts and a streams. Dashed orange lines show the boundaries of the alerting regions for Seismic Network stations (green triangles): NCSS, Northern Celifornia Seismic System stations (blue triangles); and SCSN, Southern California Seismic Network stations (red triangles).

strong ground motions, and hundreds more are strong-motion stations that lack the real-time data communications required to contribute to EEW. Therefore, there is currently an insufficient number of stations to provide fast reliable alerts in all the urban areas of the West Coast, although the Los Angeles and San Francisco Bay areas have better sensor coverage than most areas. To cover all earthquake source areas and provide robust EEW for the West Coast, the implementation plan estimates that a total of 1,675 seismic stations are needed (Given et al., 2014). The plan also calls for 300 real-time GNSS stations, but the optimal number and distribution of geodetic stations has not yet been finalized. Both CISN and PNSN are actively upgrading existing stations and constructing new ones for ShakeAlert with a combination of federal, state, and private funding. 
Hundreds of real-time high-precision GNSS stations are now becoming available on the West Coast (Mencin et al., 2013), and these may contribute to the ShakeAlert system's ability to characterize large events, especially by modeling the location and extent of the fault rupture (Allen and Ziv, 2011; Böse et al., 2013). Recently, scientists have developed algorithms that use real-time GNSS data to estimate magnitudes for large earthquakes $(\mathbf{M}>6.0)$ and solve for the distribution of fault slip (Grapenthin et al., 2014; Minson et al., 2014; Crowell et al., 2016). Mapping the evolving rupture is important for calculating the magnitude of large events and for correctly estimating the intensity that will result across a region. Potential use of real-time high-rate GNSS in the ShakeAlert system is driving efforts to make those data streams faster, more reliable, and more uniform across the operators of these networks. The real-time fault rupture information may also allow statistical on-the-fly estimates of how far a fault will ultimately rupture before it is finished (Böse and Heaton, 2010).

\section{Field Telemetry}

The ANSS stations that contribute to ShakeA-

lert send continuous real-time data back to one of three Tier 1 processing centers via some combination of radio, governmentowned microwave system, commercial cellular, commercial internet, satellite, and partner-owned telemetry systems. This heterogeneity is, in part, the result of the geographical availability of various telemetry options. Historically, this path diversity is viewed as a strength of the overall system because it minimizes single points of failure in seismic data delivery and makes it less likely that adjacent stations will be knocked off the air by a failure of one telemetry path.

For the ShakeAlert system to be robust enough to issue public alerts, its network telemetry must be reliable, robust, and sustainable, particularly during the strong ground shaking and heavy telecommunications congestion that will come with a large earthquake. USGS is exploring all available telecommunications technologies, as well as their capabilities, limitations, features, and costs, so that they can develop an evolutionary plan in support of EEW. If budgets allow, data paths can be made more reliable by engineering redundant data paths from centers to regional collection hubs or even to individual stations.

\section{Central Processing Architecture}

Today, the three ANSS Tier 1 centers in Seattle, Washington, Berkeley/Menlo Park, California, and Pasadena, California, coordinate the day-to-day earthquake data analysis and product creation for the West Coast. The ShakeAlert system has been organized using this same structure; EEW data processing and alert generation are being done by these same centers, and each center serves as a backup for the others (Fig. 2).
All seismic data are brought into the centers by various methods depending on the region's seismic network hardware, and then they are inserted into an Earthworm ring (i.e., the wavering; Johnson et al., 1995; Friberg et al., 2010) from which all the EEW algorithms will obtain their data (Fig. 2). The Earthworm waveform processing library software package provides a common framework for the processing of real-time waveforms. It is implemented as a set of algorithm classes that are used to create a processing pipeline for each station, each of which can contain one or more data channels (usually Z, E, and $N$ ). Several types of waveform feeders read raw data packets, parsing them into time-aligned packages of user-defined lengths.

The two independent point-source algorithms in the current system that compute EEW solution parameters are Onsite (which uses a $\tau_{c}-P_{d}$ method based on a high-pass filtered displacement period and amplitude parameter) (Kanamori, 2005; Wu et al., 2007; Böse et al., 2009), and ElarmS (which uses a $P_{d}$ method that is based only on the displacement amplitude parameter) (Allen and Kanamori, 2003; Allen, 2007; Allen et al., 2009; Kuyuk and Allen, 2013; Kuyuk et al., 2013). An envelope method, Virtual Seismologist (Cua and Heaton, 2007), was originally included in a California-only version 1.0 of the Production Prototype, but it has now been retired. An algorithm that produces a finite-fault line-source solution, FinDer (Böse et al., 2012), is being tested to assess whether or not it should be added to the system.

The ShakeAlert system is modular and distributed in design (Fig. 2). Each algorithm has a module that examines ground-motion data from the field sensors and derives the 
ShakeAlert Software Schematic

Production Prototype V1.2

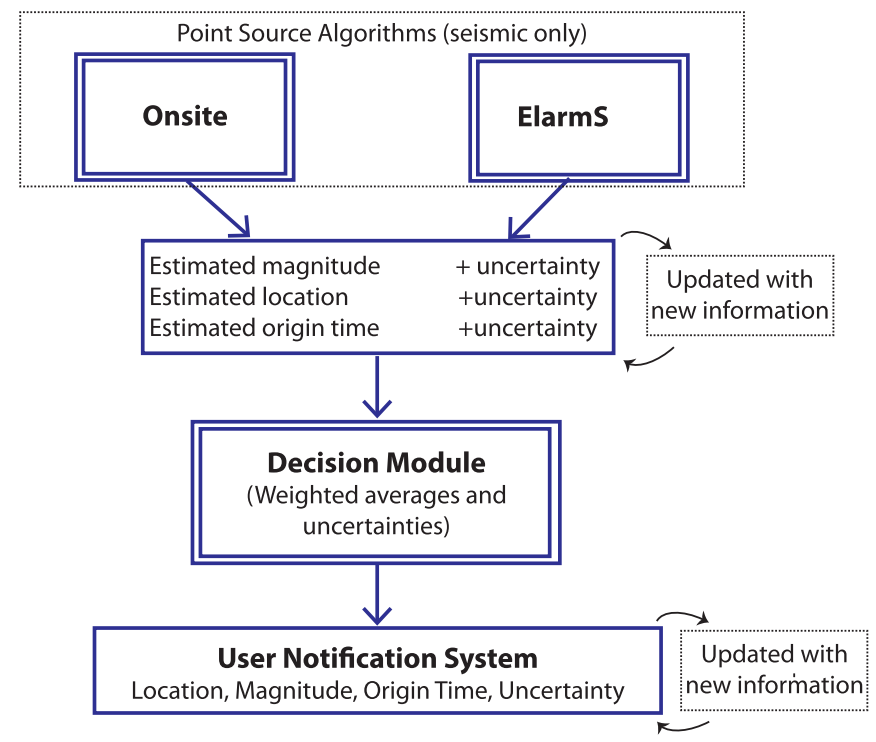

A Figure 3. ShakeAlert software schematic showing the data flow for a single processing thread. The system has multiple redundant threads that share data and synchronize notification streams.

parameters appropriate to its method (shown schematically in Fig. 2). These modules run at each Tier 1 processing center, on the set of station data streams available at each center. No one center has access to all West Coast station data. The modules could potentially also run at other data collection points or even on individual station hardware. The derived parameters are published as messages using ActiveMQ, an open-source enterprise-level message broker. These brokers are meshed to make all messages available across the entire system. Each algorithm also has an event module that associates the parametric messages to independently detect earthquakes and compute location, magnitude, origin time, and likelihood estimates that are continually updated as data is being continuously received, until the event is over. Like the parameters, these event estimates are published as messages to the entire system. The event messages are consumed by six redundant geographically distributed decision modules (DM) that combine the results by means of weighted averaging. Then, they send a synoptic view of the evolving earthquake to users as a stream of XMLformatted event notifications via ActiveMQ (Henson et al., 2012). This process is shown schematically in Figure 3.

ShakeAlert is designed with both heterogeneous and homogeneous parallel redundancy. Heterogeneous redundancy is provided through the running of multiple independent detection algorithms. Homogeneous redundancy is accomplished through the running of multiple redundant instances of the full ShakeAlert processing thread, from data analysis to alert creation, at each center (Fig. 2). These threads exchange all parameters and solutions, thus allowing each thread to use all available data to independently detect and characterize earthquakes and send event detection information to the redundant
DMs. Each DM evaluates and combines the information to create a single unified stream of messages that updates continuously as the earthquake progresses. It is impossible for distributed systems to guarantee perfect consistency, availability, and partition tolerance (Gilbert and Lynch, 2002). In the ShakeAlert design, availability is the most important requirement; thus, ShakeAlert cannot guarantee that the results will always be consistent among all DM instances. However, the DM results will be the same or very nearly the same under normal conditions where each receives the same inputs from the message brokers. In the case of a failure somewhere in the system (for example, network partitioning), delivering slightly inconsistent messages to users is preferable to failure to deliver to some users. Transmission times of messages passed between processing centers were examined in April 2017 to find the means and standard deviations of message latencies for centerto-center paths over the public internet. For packets sent from Pasadena, California, to Berkeley, California, the mean latency was found to be $5 \mathrm{~ms}$ (standard deviation $\sigma=30 \mathrm{~ms}$ ). From Berkeley to Pasadena, the mean latency is $6 \mathrm{~ms}(\sigma=68 \mathrm{~ms})$; from Pasadena to Seattle, Washington, it is $10 \mathrm{~ms}$ $(\sigma=80 \mathrm{~ms})$; from Berkeley to Seattle, it is $20 \mathrm{~ms}$ $(\sigma=100 \mathrm{~ms})$; from Menlo Park, California to Seattle, it is $10 \mathrm{~ms}(\sigma=10 \mathrm{~ms})$; and from Pasadena to Seattle, it is $10 \mathrm{~ms}(\sigma=80 \mathrm{~ms})$.

All major software components of the system, including each algorithm, publish a state-of-health heartbeat message approximately every $5 \mathrm{~s}$. The DM relays these messages to enduser applications. The heartbeat aggregator (HA) summarizes the individual heartbeat messages and sends out an aggregated summary message approximately every $20 \mathrm{~s}$. This aggregated message is used to determine overall system health. There are multiple HA instances monitoring the current Production Prototype servers that are running at each center (Fig. 2).

Station metadata is provided to all algorithms in a uniform file format, which simplifies metadata management and ensures that all modules agree on station parameters. Each waveform processing center must provide an up-to-date list of good and bad channels that are of sufficient quality for use in the system. Currently, almost all raw waveform data from a given region are processed only at the regional ANSS center, a potential fragility in the system that could be addressed if dual telemetry paths were to be implemented from field stations to deliver data to multiple sites.

Additional Production Prototype central processing architecture components include (1) source code and build repositories in which algorithm developers check in/out code, and in which binary builds and any associated configuration files are stored and tagged, (2) a real-time in situ (staging) server at each site, and (3) two redundant Production Prototype servers at each site with failover capabilities. All Production Prototype servers, with the exception of those at Menlo Park, send alert streams. The source code management (e.g., open-source subversion $[\mathrm{SVN}]$ ) software versioning and revision control system tool is used to manage version numbers associated with files in repositories. All Production Prototype servers run a uni- 
form version of Linux that is installed, updated, and patched using configuration management software that ensures a uniform build across all servers and networks. This software can automate update procedures to maintain consistency and dependability across the computer network, which in this case includes servers at the ShakeAlert centers. An open-source enterprise-class software application (see Data and Resources) is used to regularly monitor system state-of-health including services, EEW applications, and basic operating system processes.

Prior to declaring Production Prototype 1.0 ready for external users, all servers that hosted critical system functions were required to meet several test criteria. One of the most basic of these was that all operating system environments, as well as the ShakeAlert-specific algorithms, must be at the same revision number and be under uniform configuration control management. Additional capabilities that have been (and continue to be) tested include ensuring the continued operation, without interruption, of critical capabilities during modifications and updates to the (1) system level environment, (2) interserver messaging tool configuration, (3) ShakeAlert algorithms, and (4) application configuration and station configuration files. The Production Prototype system also underwent failure-mode testing; that is, the system's architectural robustness was tested by intentionally creating various plausible system failure modes, including but not limited to: loss of the redundant instances within a Tier 1 center, loss of a Tier 1 center, and loss of connection between centers. Additionally, tests of completely swapping out all hardware and using the configuration management software to rebuild the host computer and bring it back to its previous state took less than $2 \mathrm{hrs}$. The four sites coordinate to patch servers regularly, and each server is routinely scanned for vulnerabilities. Each server runs the minimum number of services required to perform ShakeAlert tasks; then, all other unnecessary services are stopped, and ports are closed. Communication among servers takes place using dedicated controls and a minimum number of people with root and configuration management software access.

\section{Sending Alerts and Data Streams}

The ShakeAlert system delivers one primary data product that contains information about the evolving earthquake, which includes its origin time, location, magnitude, likelihood, and the extent and distribution of the fault slip. This XML stream can optionally include direct measurements of peak ground motions from sensors and other parameters of engineering interest. This event notification stream is received and interpreted by client applications. One such application, called UserDisplay, is supplied to beta users to run on their local computers. The UserDisplay application translates the earthquake magnitude and location into an estimate of arrival time and expected peak shaking at the user's location and displays the results graphically (Fig. 4). Another example is MyEEW, a cell phone app developed by Berkeley Seismological Lab (Strauss and Allen, 2016). Other message formats are being developed to allow for flexible integration into mobile phone and other mass-distribution alert applications, engineering applications, and other uses.

The second primary product is under development and describes the area in which a predetermined threshold of shaking will be met or exceeded. Users within that area can then be notified that strong shaking is coming. The threshold value for which public alerts will be issued has not yet been agreed upon by the emergency management authorities; two proposed thresholds are modified Mercalli intensity (MMI) IV (the level at which shaking is felt) and MMI VI (the level at which damage becomes likely). The characteristics of this type of alert are being designed to accommodate the limitations of most current public alert delivery systems.

ShakeAlert notifications will be sent over available public alert systems to the extent that the capabilities of these systems allow. For example, the event messages from ShakeAlert are being converted to Common Alert Protocol (CAP) format. $\mathrm{CAP}$ is a data format for exchanging public warnings and emergency messages based on XML (see Data and Resources). CAP warning messages can be distributed to multiple warning systems to end users. For example, CAP-formatted AMBER (America's 
Missing: Broadcast Emergency Response) alerts and hazard alerts are broadcast via the Integrated Public Alert and Warning System (IPAWS) operated by the FEMA (2010). This system can activate popup messages on television screens and audio alerts over commercial radio and National Oceanic and Atmospheric Administration weather radio. In addition, Wireless Emergency Alerts (WEA) can send messages to wireless devices, such as cell phones. However, currently, the delivery delays in IPAWS/WEA are too large to provide timely delivery of EEW to alerts (Federal Communications Commission [FCC], 2016).

Alerts may also be sent via state, county, and local government alert and notification systems; they can also be sent through private redistribution channels, such as cell phone apps, push notification channels, social media providers, and other alert technologies as they develop. Commercial mass notification companies may redistribute alerts to their customers through various technologies, including radio data systems that are integrated with their other product offerings. Because the private sector will be critical to the successful public distribution of ShakeAlert, project partners are currently working with companies to develop a variety of alert distribution channels and end-user implementation capabilities.

\section{End-User Applications}

The EEW end users are both people and systems. The most obvious human response to a ShakeAlert message is to move to a safe location and prepare for shaking. This is consistent with the earthquake preparedness community's general advice to drop, cover, and hold on during an earthquake. This allpurpose message should be re-examined, given that EEW may allow enough time to take other protective actions. Examples of these actions include stopping the operation of dangerous devices at home or in the office, and evacuating unsafe structures in extreme cases. Furthermore, an EEW-enabled smart phone or other device may be able to provide context-specific instructions such as to pull over if driving, move away from windows if in a high-rise, etc. Benefits of ShakeAlert will also result from actions taken by automated systems that can react quickly in predetermined or preprogrammed ways to protect lives and property. An example of a practical application of ShakeAlert messages has been implemented by San Francisco's Bay Area Rapid Transit (BART) district, which in August 2012 began slowing and stopping trains in response to strong ground shaking to reduce the likelihood of derailment (McPartland, 2013). NBCUniversal in Los Angeles is testing the use of ShakeAlert messages at a fire station on its property to automatically open fire station doors and send audible alerts over intercom systems and to fire trucks.

Extensive outreach and education to both public and institutional users is ensuring that EEW has the maximum beneficial effect. All potential users must be instructed about the limitations and reliability of the warning information, in addition to the actions they are to take upon receiving a warning. Decision makers in both the public and private sectors will need to be informed of the capabilities of the ShakeAlert system, so that they can most effectively integrate earthquake alerts into their organization's earthquake mitigation planning. Private sector companies that integrate ShakeAlert into their product offerings can facilitate this education process.

The opportunities created by full implementation of ShakeAlert in the United States are stimulating a new private EEW industry that is developing products to distribute and utilize alerts. Private companies may also provide onsite systems to augment ShakeAlert for particularly vulnerable infrastructure. A local onsite system could potentially provide a faster warning when an event is very close to a user's facility and give the added assurance offered by having two independent systems. Such systems are in operation in Japan (Kanda et al., 2009; Takamatsu, 2009). Once public EEW is routine for the West Coast, the USGS may expand ShakeAlert to additional areas of the United States. Obvious candidates are regions that are at high seismic risk (areas with significant earthquake hazard and dense populations) (FEMA, 2008). The spread of ShakeAlert is driven largely by the local stakeholders and their ability to gather the support necessary to fund the building and operation of the system in their area. The need for EEW in an area is amplified by the existence of particularly vulnerable or valuable infrastructure (e.g., ports, power plants, and military installations) that may benefit from advance warning of ground shaking.

\section{CONCLUSIONS}

The EEW ShakeAlert project is built on the foundation of the existing nationwide ANSS seismic network infrastructure that has enabled the creation of a public EEW system in the United States. ShakeAlert is now in the Production Prototype 1.2 stage of implementation on the entire West Coast of the United States. The objective of ShakeAlert is to provide people with seconds to minutes of warning time, so that they can take protective actions before peak shaking arrives at their locations (Given et al., 2014). ShakeAlert leverages the nationwide ANSS seismic network infrastructure; this federation of regional networks runs algorithms that conduct waveform processing, event originators and associators, and alert generators. The two foundational EEW algorithms in the system are Onsite, which uses a method that is based on ground-motion period and high-pass filtered displacement amplitude parameters $\left(\tau_{c}-P_{d}\right)$; and ElarmS, which uses a method that is based on the high-pass filtered displacement amplitude $\left(P_{d}\right)$. These algorithms examine the same raw ground motion from seismometers, but they independently detect earthquakes and make location, magnitude, origin time, and likelihood estimates that are updated during an earthquake. The DM algorithm uses estimates of the source parameters and uncertainties to calculate, update, and report the most probable magnitude, location, and origin time estimates during the evolving earthquake. The HA sends messages to report overall system health. Additional components include a software repository, a testing and certification platform, redundancy in server hardware and all EEW-related software, and failure-mode capability. The prototype ShakeAlert system architecture has been designed to provide redundancy and robustness that is necessary for system continuity and reliability. 
Alerts may be sent out via state, county, and local government alert and notification systems. In addition, private redistribution channels, such as cell phone apps, push notification channels, and social media providers may distribute alerts. ShakeAlert notifications may be sent over public alerts systems using the CAP format, as well as to one or more FEMA-Integrated Public Alert and Warning System recipients. With a few seconds of warning, ShakeAlert can potentially trigger actions that prevent immediate damage, injury or death, and speed recovery. School children can drop, cover, and hold on, and crowds in theaters and sports venues can be forewarned and given instructions to prevent panic. Workers in factories, construction sites, and hospitals can stop operations with dangerous equipment or evacuate dangerous areas. Fire station doors can be opened to prevent jamming. Heavy equipment such as trains, elevators, and cranes can automatically stop in safe positions. Pipeline valves can be shut, preventing spills. EEW alerts can be particularly valuable after a large earthquake because aftershocks may shake already weakened structures, endangering rescue and repair workers in hazardous situations.

\section{DATA AND RESOURCES}

Latency data are available upon request by contacting the following email: kohler@caltech.edu. Some plots were made using the Generic Mapping Tools v.4.2.1 (www.soest.hawaii.edu/ gmt, last accessed November 2017; Wessel and Smith, 1998). Additional information about the open-source enterprise-class software application can be found at Nagios.org. For Common Alert Protocol (CAP) format, see https://www.fema.gov/ common-alerting-protocol (last accessed November 2017). $\mathbf{<}$

\section{ACKNOWLEDGMENTS}

The authors wish to acknowledge the entire earthquake early warning research team, many of whom provided valuable discussions that helped inform the writing of this article. Particular thanks go to Tom Heaton, Richard Allen, and John Vidale. The authors thank Associate Editor Brendan Crowell, U.S. Geological Survey (USGS) internal reviewers Sarah Minson and Glenn Biasi, as well as two anonymous reviewers for their useful comments.

\section{REFERENCES}

Allen, R. M. (2007). The ElarmS earthquake early warning methodology and application across California, in Earthquake Early Warning Systems, P. Gasparini, G. Manfredi, and J. Zschau (Editors), Springer, Berlin, Heidelberg, ISBN-13 978-3-540-72240-3.

Allen, R. M., and H. Kanamori (2003). The potential for earthquake early warning in southern California, Science 300, 786-789.

Allen, R. M., and A. Ziv (2011). Application of real-time GPS to earthquake early warning, Geophys. Res. Lett. 38, no. 16, doi: 10.1029/ 2011 GL047947.

Allen, R. M., H. Brown, M. Hellweg, O. Khainovski, P. Lombard, and D. Neuhauser (2009). Real-time earthquake detection and hazard assessment by ElarmS across California, Geophys. Res. Lett. 36, L00B08, doi: 10.1029/2008GL036766.

Bakun, W. H., F. G. Fischer, E. G. Jensen, and J. VanSchaack (1994). Early warning system for aftershocks, Bull. Seismol. Soc. Am. 84, no. 2, $359-365$.

Böse, M., and T. Heaton (2010). Probabilistic prediction of rupture length, slip and seismic ground motions for an ongoing rupture -Implications for early warning for large earthquakes, Geophys. J. Int. 183, 1014-1030, doi: 10.1111/j.1365-246X.2010.04774.x.

Böse, M., E. Hauksson, K. Solanki, H. Kanamori, Y.-M. Wu, and T. Heaton (2009). A new trigger criterion for improved real-time performance of Onsite earthquake early warning in southern California, Bull. Seismol. Soc. Am. 99, no. 2A, doi: 10.1785/ 0120080034.

Böse, M., T. Heaton, and E. Hauksson (2012). Real-time finite fault rupture detector (FinDer) for large earthquakes, Geophys. J. Int. 191, no. 2, 803-812.

Böse, M., T. Heaton, and K. Hudnut (2013). Combining real-time seismic and GPS data for earthquake early warning, $A G U$ Fall Meeting Abstracts Vol. 1, p. 5.

Bozorgnia, Y., and V. V. Bertero (2004). Earthquake Engineering: From Engineering Seismology to Performance-Based Engineering, International Code Council, International Standard Book Number-13: 978-0-203-48624-5, CRC Press, Boca Raton, Florida.

Clayton, R., T. Heaton, M. Chandy, A. Krause, M. Kohler, J. Bunn, R. Guy, M. Olson, M. Faulkner, M. H. Cheng, et al. (2011). Community seismic network, Ann. Geophys. 54, no. 6, doi: 10.4401/ag-5269.

Clayton, R. W., T. Heaton, M. Kohler, M. Chandy, R. Guy, and J. Bunn (2015). Community seismic network: A dense array to sense earthquake strong motions, Seismol. Res. Lett. 86, 1354-1363, doi: 10.1785/0220150094.

Cochran, E. S., M. D. Kohler, D. Given, S. Guiwits, M.-A. Meier, M. Ahmand, I. Henson, J. Andrews, and R. Hartog (2017). Earthquake early warning ShakeAlert system: Testing and certification platform, Seismol. Res. Lett. doi: 10.1785/0220170138.

Cochran, E. S., J. F. Lawrence, C. Christensen, and R. S. Jakka (2009). The Quake-Catcher Network: Citizen science for expanding seismic horizons, Seismol. Res. Lett. 80, 26-30.

Crowell, B. W., D. A. Schmidt, P. Bodin, J. E. Vidale, J. Gomberg, J. R. Hartog, V. C. Kress, T. I. Melbourne, M. Santillan, S. E. Minson, et al. (2016). Demonstration of the Cascadia G-FAST geodetic earthquake early warning system for the Nisqually, Washington earthquake, Seismol. Res. Lett. 87, doi: 10.1785/0220150255.

Cua, G., and T. Heaton (2007). The virtual seismologist (VS) method: A Bayesian approach to earthquake early warning, in Earthquake Early Warning Systems, P. Gasparini, G. Manfredi, and J. Zschau (Editors), Springer, Berlin, Heidelberg, ISBN-13 978-3-540-72240-3.

Federal Communications Commission (FCC) (2016). Capacity of the Integrated Public Alert and Warning System to Deliver Sensor-Based Earthquake Early Warnings: An Engineering Analysis, FCC White Paper, Public Safety and Homeland Security Bureau, Washington, D.C.

Federal Emergency Management Agency (FEMA) (2008). HAZUS-MH estimated annualized earthquake losses for the United States, FEMA 366, Washington, D.C.

FEMA (2010). Integrated Public Alert and Warning System (IPAWS), Emergency Management Agency, available at http://www.fema. gov/emergency/ipaws (last accessed November 2017).

Friberg, P., S. Lisowski, I. Dricker, and S. Hellman (2010). Earthworm in the 21st century, Geophys. Res. Abstr. 12, Abstract, EGU 2010-12654.

Gilbert, S., and N. Lynch (2002). Brewer's conjecture and the feasibility of consistent, available, partition-tolerant web services, $A C M S I-$ GACT News 33, no. 2, 51-59.

Given, D., E. Cochran, T. Heaton, E. Hauksson, R. Allen, M. Hellweg, J. Vidale, and P. Bodin (2014). Technical implementation plan for the ShakeAlert production prototype system-An earthquake early warning system for the West Coast of the United States, U.S. Geol. Surv. Open-File Rept. 2014-1097, 25 pp., doi: 10.3133/ofr20141097. 
Grapenthin, R., I. A. Johanson, and R. Allen (2014). Operational realtime GPS-enhanced earthquake early warning, J. Geophys. Res. 119, doi: 10.1002/2014JB011400.

Graves, R. W., A. Pitarka, and P. G. Somerville (1998). Ground-motion amplification in the Santa Monica area: Effects of shallow basinedge structure, Bull. Seismol. Soc. Am. 88, no. 5, 1224-1242.

Henson, I., D. Neuhauser, and R. Allen (2012). CISN ShakeAlert: Decision module enhancements for earthquake alerts, $A G U$ Fall Meeting Abstracts Vol. 1, p. 2433.

Hoshiba, M., O. Kamigaichi, M. Saito, S. Tsukada, and N. Hamada (2008). Earthquake early warning starts nationwide in Japan, Eos Trans., $A G U 89$, no. 8, 73-74.

Jaiswal, K. S., M. D. Petersen, K. Rukstales, and W. S. Leith (2015). Earthquake shaking hazard estimates and exposure changes in the conterminous United States, Earthq. Spectra 31, no. S1, S201-S220.

Johnson, C. E., A. Bittenbinder, B. Bogaert, L. Dietz, and W. Kohler (1995). Earthworm: A flexible approach to seismic network processing, Incorporated Research Institutions for Seismology (IRIS) Newsletter 14, 1-4.

Kanamori, H. (2005). Real-time seismology and earthquake damage mitigation, Annu. Rev. Earth Planet. Sci. 33, 195-214.

Kanda, K., T. Nasu, and M. Miyamura (2009). Practical site-specific earthquake early warning application, J. Disast. Res. 4, 251-259.

Kuyuk, H. S., and R. M. Allen (2013). A global approach to provide magnitude estimates for earthquake early warning alerts, Geophys. Res. Lett. 40, 6329-6333, doi: 10.1002/2013GL058580.

Kuyuk, H. S., R. M. Allen, H. Brown, M. Hellweg, I. Henson, and D. Neuhauser (2013). Designing a network-based earthquake early warning algorithm for California: ElarmS-2, Bull. Seismol. Soc. Am. 104, 162-173, doi: 10.1785/0120130146.

Lancieri, M., and A. Zollo (2008). A Bayesian approach to the real-time estimation of magnitude from the early $\mathrm{P}$ and $\mathrm{S}$ wave displacement peaks, J. Geophys. Res. 113, no. B12302, doi: 10.1029/2007JB005386.

Lawrence, J. F., E. S. Cochran, A. Chung, A. Kaiser, C. M. Christensen, and R. Allen (2014). Rapid earthquake characterization using MEMS accelerometers and volunteer hosts following the M 7.2 Darfield, New Zealand, earthquake, Bull. Seismol. Soc. Am. 113, 184-192.

McPartland, J. (2013). Using earthquake early warning in the Bay Area Rapid Transit System, AGU Fall Meeting Abstracts Vol. 1, p. 2.

Meier, M.-A. (2017). How "good" are real-time ground motion predictions from earthquake early warning systems?, J. Geophys. Res. 122, doi: 10.1002/2017JB014025.

Mencin, D., C. Meertens, G. Mattioli, K. Feaux, S. Looney, C. Sievers, and K. Austin (2013). UNAVCO GPS high-rate and real-time products and services: Building a next generation geodetic network, EGU General Assembly Conference Abstracts, Vol. 15, p. 12314.

Minson, S., J. Murray, J. Langbein, and J. Gomberg (2014). Real-time inversions for finite fault slip models and rupture geometry based on high-rate GPS data, J. Geophys. Res. 119, no. 4, doi: 10.1002/ 2013JB010622.

Minson, S. E., S. Wu, J. L. Beck, and T. H. Heaton (2017). Combining multiple earthquake models in real time for earthquake early warning, Bull. Seismol. Soc. Am. doi: 10.1785/0120160331.

Murphy, S., and S. Nielsen (2009). Estimating earthquake magnitude with early arrivals: A test using dynamic and kinematic models, Bull. Seismol. Soc. Am. 99, 1-23.

Nakamura, Y. (1988). On the urgent earthquake detection and alarm system (UrEDAS), Proc. of the 9th World Conf. on Earthquake Engineering, Tokyo-Kyoto, Japan, Vol. VII, 673-678.

Olson, E. L., and R. M. Allen (2005). The deterministic nature of earthquake rupture, Nature 438, no. 7065, 212-215.

Papazoglou, A. J., and A. S. Elnashaj (1996). Analytical and field evidence of the damaging effect of vertical earthquake ground motion, Earthq. Eng. Struct. Dynam. 25, 1109-1137.

Satriano, C., Y.-M. Wu, A. Zollo, and K. Kanamori (2011). Earthquake early warning: Concepts, methods and physical grounds, Soil Dynam. Earthq. Eng. 31, 106-118.
Strauss, J. A., and R. M. Allen (2016). Benefits and costs of earthquake early warning, Seismol. Res. Lett. 87, no. 3, 765-772.

Takamatsu, K. (2009). Application of the earthquake early warning system for the OKI semiconductor factory, The 2nd International Workshop on Earthquake Early Warning, Kyoto, Japan, April 2009.

Thelen, W. A., A. J. Hotovec-Ellis, and P. Bodin (2016). Feasibility study of earthquake early warning (EEW) in Hawaii, U.S. Geol. Surv. Open-File Rept. 2016-1172, 30 p.

U.S. Geological Survey (USGS) (1999). An assessment of seismic monitoring in the United States; requirement for an Advanced National Seismic System, U.S. Geol. Surv. Circular 1188, 55 pp.

USGS (2014). ANSS Participation Policy, Version 1.0, available at http:// earthquake.usgs.gov/monitoring/anss/docs/ANSS_Participation_Policy.pdf (last accessed November 2017).

Wessel, P., and W. H. F. Smith (1998). New, improved version of the Generic Mapping Tools released, Eos Trans. $A G U$ 79, 579.

Wu, Y.-M., H. Kanamori, R. Allen, and E. Hauksson (2007). Determination of earthquake early warning parameters, tau-c and $\mathrm{Pd}$, for southern California, Geophys. J. Int. 170, 711-717.

Wu, Y.-M., T.-C. Shin, and Y.-B. Tsai (1998). Quick and reliable determination of magnitude for seismic early warning, Bull. Seismol. Soc. Am. 88, no. 5, 1254-1259.

Monica D. Kobler Claude Felizardo Rayo Bhadha

California Institute of Technology 1200 East California Boulevard Pasadena, California 91125 U.S.A. kohler@caltech.edu

Elizabeth S. Cochran

Doug Given

Steve Guiwits

Stan Schwarz

U.S. Geological Survey 525 South Wilson Avenue Pasadena, California 91106 U.S.A.

Doug Neuhauser Ivan Henson

Stephen Thompson University of California, Berkeley McCone Hall, 215 Haviland Path \#4760 Berkeley, California 94720 U.S.A.

Renate Hartog

Paul Bodin

Victor Kress

University of Washington 4000 15th Avenue NE Seattle, Washington 98195 U.S.A.

\author{
Jeff Brody \\ U.S. Geological Survey \\ 345 Middlefield Road \\ Menlo Park, California 94025 U.S.A.
}

Published Online 6 December 2017 